\title{
Behaviour of European wild boars (Sus scrofa) in connection with farrowing in an enclosure
}

Annelie Andersson, Riikka Äänismaa, Jenni Huusko and Per Jensen

\section{Linköping University Post Print}

N.B.: When citing this work, cite the original article.

Original Publication:

Annelie Andersson, Riikka Äänismaa, Jenni Huusko and Per Jensen, Behaviour of European wild boars (Sus scrofa) in connection with farrowing in an enclosure, 2011, Mammalian Biology, (76), 3, 332-338.

http://dx.doi.org/10.1016/j.mambio.2011.01.010

Copyright: Elsevier Science B.V. Amsterdam

http://www.elsevier.com/

Postprint available at: Linköping University Electronic Press

http://urn.kb.se/resolve?urn=urn:nbn:se:liu:diva-57983 


\title{
Behaviour of European wild boar (Sus scrofa) in connection with farrowing in an enclosure
}

Running title: Farrowing behaviour of wild boars

\author{
Annelie Andersson, Riikka Äänismaa ${ }^{1}$, Jenni Huusko ${ }^{2}$, Per Jensen* \\ IFM Biology, Division of Zoology, Linköping University, SE-581 83 Linköping, Sweden; ${ }^{1}$ Present \\ address: Regea Institute for Regenerative Medicine, Biokatu 12, 6th floor, 33520 Tampere, Finland; \\ ${ }^{2}$ Present address: Department of Biotechnology and Molecular Medicine, Neulaniementie 2, PL \\ 1627, 70211 Kuopio, Finland
}

* Corresponding author: e-mail address: per.jensen@ @ifm.liu.se; phone: +46 13 281298; fax: +46 13 137568 


\begin{abstract}
Wild boars (Sus scrofa) are often kept in enclosures for hunting or meat production purposes in Sweden. The sows are known to undergo behavioural changes in connection with farrowing and their natural behaviours may be compromised by the limited area of the enclosure. The aim of this study was to quantitatively describe wild boar sows' behaviour when farrowing in an enclosure. A field study was carried out in a hunting enclosure, where 1200 hours of behavioural recordings and data from 22 farrowings were collected. According to the results, the farrowing period could be divided into 3 phases: pre-farrowing, isolation and sociality phases (in relation to farrowing: day -14 to -1 , day 1 to 8 , day 9 to 14 respectively). The activity decreased during isolation and increased in the sociality phase $(\mathrm{p}<0.05)$, whereas the average distance to other individuals increased during isolation and decreased in the sociality phase $(\mathrm{p}<0.05)$. Nose contacts with other individuals increased in the isolation phase $(\mathrm{p}<0.05)$ and habitat use changed towards more protective habitats after farrowing. $68 \%$ of the nests were situated in edges between 2 habitats of different vegetation density and $73 \%$ had some kind of protection to the north. We conclude that farrowing induces a number of changes in the activity, social behaviour and habitat preference in captive European wild boars. This may need attention when enclosures for this species are designed.
\end{abstract}

Key words: wild boar; behaviour; farrowing; enclosure 


\section{Introduction}

The wild boar (Sus scrofa) is widely spread over the world and is frequently kept in captivity for different purposes. In Sweden, about 100 wild boar enclosures are used for meat production, public display, hunting and/or training of hunting dogs. It is possible that the natural behaviour of the wild boars can be compromised by the limited area and the structure of an enclosure. For example, studies from free-living and captive wild boar sows show that several behavioural changes take place in connection with farrowing (e.g.Gundlach, 1968), some of which could potentially be hindered by an insufficient space allowance. Hence, detailed studies of the behaviour under confined conditions may help improving husbandry routines and welfare regulations for the species.

Free-living wild boars are found in many different habitats such as open and dense forests, swamps and fields (Abaigar et al., 1994; Boitani et al., 1994; Spitz and Janeau, 1995). They seem to prefer different habitats for different activities, both in confinement (Blasetti et al., 1988) and in the wild (Massei and Genov, 1995). Their activity pattern has been demonstrated to be diurnal in enclosures (Gundlach, 1968) and nocturnal in the wild (Mauget, 1980b) and this dissimilarity might be explained by the animals adjusting to human hunting pressure in the wild (Stegeman, 1938;

Briedermann, 1971a). In confinement the wild boars are inactive more than half of their time and the rest of the time is mostly spent on feeding and locomotion (Blasetti et al., 1988) which is consistent with results from free living wild boars (Mauget, 1980a).

The social organisation of wild boars is highly dynamic and varies between seasons, with the basic unit consisting of related sows of several generations and their latest offspring (Gundlach, 1968; Dardaillon, 1988; Kaminski et al., 2005). As other social animals they form a hierarchy, which is maintained by nose contacts and agonistic behaviours (Beuerle, 1975; Dardaillon and Teillaud, 1987). The sows' reproduction is synchronised within a group (Delcroix et al., 1990) and the solitary 
male joins the sows during the autumn when they come into estrous (Briedermann, 1971b;

Dardaillon, 1988). The gestation lasts for about 115 days (Henry, 1968) and results in a farrowing season during the spring. Both in confinement (Gundlach, 1968) and in the wild (Dardaillon, 1988), wild boar sows are reported to isolate from the group a couple of days before farrowing to find a place to build a nest where they give birth to their piglets. In contrast to other ungulates the wild boar young are well developed (Gundlach, 1968) and the sow gives birth to more than 4 young on average (Carranza, 1996). The farrowing nests of free-living sows are found in relatively protective habitats as e.g. edges to marsh land (Dardaillon, 1986) or dense forests and often in slopes facing the south, south west and east (Janeau and Spitz, 1984). After parturition, the sow stays in the nest for up to 2 weeks before joining the family group again, in which the young are reared communally in nursing groups consisting of 2 or more sows with piglets of about the same age (Gundlach, 1968; Delcroix et al., 1985; Teillaud, 1986; Dardaillon, 1988).

Several studies report behavioral changes in connection with farrowing in captivity and in the wild, e.g. an increased aggression (Gundlach, 1968; Martys, 1982; Hirotani and Nakatani, 1987) and an increased activity before farrowing (Eguchi et al., 1998), and a decrease in agonistic behaviours after farrowing (Teillaud, 1986). Moreover, the activity decreases in wild boar sows with young piglets (Cousse and Janeau, 1992) and they tend to prefer protective and dense habitats (Spitz and Janeau, 1995; Fernández-Llario et al., 1996). However, in contrast to domestic pigs (Jensen et al., 1987; Jensen and Redbo, 1987; Jensen et al., 1991), systematic and detailed behaviour data, based on long-time recordings of individual sows during farrowing are scarce. Such data are crucial in order to understand the details of the environmental requirements of farrowing wild boars.

The aim of this study was to quantitatively describe the behaviour of wild boar sows in connection with farrowing in an enclosure. Specifically, we aimed to quantify activity changes, 
habitat use, social behaviour and social isolation. The purpose was to collect data which would provide a better understanding of the environmental needs of wild boars kept in confined conditions. 


\section{Material and methods}

\section{Ethical note}

This research was carried out under license from the Linköping Ethical committee on animal experiments.

\section{Enclosure and management}

The study was conducted in February to April in 2003, 2004 and 2005 in a hunting enclosure with European wild boars, in Östergötland, Sweden. The enclosure measured 10 ha, and was relatively hilly and very heterogeneous with varied habitats such as dense spruce, leaf, open pine and mixed forests, fields, rocks and a marsh. There were natural and man made water sources. Normal housing routines were followed, which meant feeding about once a week by the animal keeper. The animals were fed on ground with household waste, pig pellets, raw potatoes and bread and could also find some natural food in the enclosure. Water could be found in the existing water sources and the animals ate snow and ice when available. The confined population varied in number between ten and 30 animals, i.e. one to two boars, four to ten sows, piglets and yearlings. Culling was done by naturalistic hunts in the enclosure or by the keeper shooting the animals at a close distance during feeding.

\section{Animals}

Twelve European wild boar sows were included in the study. Their relationships and parity were not fully clear. However, it was known that five of them were nulliparus and six were multiparus (one of unknown parity) and all but one was related. Nine of the sows were used to humans and were undisturbed when being followed by foot at a distance of a couple of meters. Two sows were highly aversive towards humans and one was recently introduced to the enclosure, so these three were not possible to follow by foot without severe disturbance; hence, these sows were used only for data 
collection on farrowing nest characters. In 2003 and 2004 the sows were paint marked on their fur for individual recognition and the markings were improved when needed. Apart from the paint markings, no interference was done with the sows. In 2005 the sows were ear marked with differently colored and numbered plastic ear tags before start of the study. No other interference was done with the sows.

In 2003 at the start of the study period there were six sows, 18 yearlings and one boar in the enclosure. These animals formed two groups which only had sporadic contact. Group 1 consisted of four sows, twelve yearlings and the boar and Group 2 consisted of two sows and six yearlings. The sows in Group 1 were estimated by the keeper to be 4 to 7 years old and the sows in Group 2 were 3 years old. All sows were used in the study, the sows in Group 2 only for data collection on farrowing nest characters. In 2004 at the start of the study period there were nine sows, 17 yearlings and one boar in the enclosure. All except one newly introduced sow formed a group. The sows were estimated to be two to eight years old. The newly introduced sow and six out of the group's eight sows were used in the study, the newly introduced sow only for data collection on farrowing nest characters. Three sows were the same as those studied in 2003. In 2005 at the start of the study period there were nine sows, 11 yearlings and two boars in the enclosure. All except one sow and one boar formed a single group. The sows were estimated to be 1 to 9 years old. All nine sows were used in the study, this year only for data collection on farrowing nest characters. Three of them had been studied before both in 2003 and 2004 and four of them were studied before only in 2004 .

\section{Methods}

In total six observers were involved in data collection. Before the start of data collection, the observers spent at least 5 days ( $~ 6$ hours/ day) following the animals in the enclosure to habituate 
the animals and to train the observers in identifying animals and behaviours. In 2003 and 2004 the data were collected by focal animal sampling (Martin and Bateson, 1993). To balance the data a rolling timetable was used for sows and observers. When observed, the sows were followed at a distance of about 1 to 50 meters and this was done during at least 14 days before the estimated farrowing day and, if possible, 14 days after farrowing. For each sow an observation day was divided into observation sessions lasting for 15 minutes, each constituting one sample. When a 15minutes session was over, a new session started over directly if the sow still was in sight. The division of the day into 15-minutes sessions was done in order to minimise data loss if the sow got lost out of sight during an observation session. Sampling methods used were instantaneous sampling with 1 minute intervals and continuous sampling (see Variables below). Farrowing nest data were collected all three seasons and as soon as possible after the parturition.

In February to April of 2003 behavioural data were collected in four sows, by three observers, during four days per week and during 4.5 hours per day and sow (Monday and Tuesday 12.30-17.00; Thursday and Friday 8.00-12.30). The data collection 2003 resulted in a total of 1407 observation samples, or 350 hours of data, and data from six farrowing nests. In February to April of 2004 behavioural data were collected in six sows, by three observers, during seven days per week and during 8.5 hours per day $(7.30-12.00,13.30-17.30)$. Each sow was studied 4.25 hours per day (7.30$9.45+13.30-15.30$ or $9.45-12.00+15.30-17.30)$ and the data collection 2004 resulted in a total of 3363 observation samples, or 840 hours of data, and data from seven farrowing nests. In February to April of 2005 one observer visited the enclosure five days per week (not less frequent than every second day). The observer controlled if any sow had left the group or could be found in a farrowing nest. Farrowing nest data were collected as soon as possible after parturition, resulting in data from nine farrowing nests. No other behavioural data were collected in this season. 


\section{Variables}

Earlier findings of wild boar and domestic pig behaviour describe a wide range of behavioural changes in farrowing period (see introduction). The variables in this study are listed in Table 1, and were partly selected from those findings. The table outlines which of the variables that were sampled with instantaneous recordings (one-min intervals) and which were sampled using continuous recording.

Habitat use was recorded by instantaneous sampling and habitat availability was estimated and calculated from a map over the enclosure. The following habitats were defined:

- Field: ground-vegetation consisting mainly of grass (32.5\% of the enclosure)

- Edge: a boarder between two different habitats which differ in vegetation layers or vegetation density; the boarder reaches $5 \mathrm{~m}$ into each habitat $(23.8 \%)$

- Mixed forest: tree-, bush- and ground-vegetation; no obvious dominant species in tree- or bush-vegetation $(17.6 \%)$

- Dense spruce forest: tree- and ground-vegetation; tree-vegetation consists of spruces that have branches at as most $0.5 \mathrm{~m}$ from the ground and where at least $50 \%$ of the branches meet between the trees $(4.0 \%)$

- Feeding area: a place where feed was brought to the animals $(0.4 \%)$

- Other habitats $(21.7 \%)$

As soon as possible after a sow had farrowed, the following nest character variables were recorded:

- Habitat where the nest was situated

- Direction of any protection or slope within 1 meter from the nest. 
Table 1. Sampling methods and definitions of the behavioural variables

\begin{tabular}{|c|c|c|c|}
\hline $\begin{array}{l}\text { Sampling } \\
\text { method }\end{array}$ & $\begin{array}{l}\text { Variable } \\
\text { group }\end{array}$ & Variable & Behaviour; definitions after Dardaillon and Teillaud (1987) \\
\hline \multirow{9}{*}{$\begin{array}{l}\text { Instantaneous } \\
\text { sampling }\end{array}$} & \multirow[t]{5}{*}{ Activities } & Resting & Sitting or lying without nursing \\
\hline & & Foraging & $\begin{array}{l}\text { Feeding: digging, rooting, grazing, keeping food in place with hoof, standing on its rear } \\
\text { legs to get food, feeding at feeding place, carrying food }\end{array}$ \\
\hline & & & Drinking \\
\hline & & Locomotion & Walking, trotting, galloping, jumping over things, swimming \\
\hline & & Nursing & $\begin{array}{l}\text { All phases in suckling as sow laying down grunting, piglets pre stimulating, ejection, } \\
\text { piglets after stimulating }\end{array}$ \\
\hline & \multirow{4}{*}{ Sociality } & other & $>20 \mathrm{~m}$ to nearest adult \\
\hline & & individuals & $0-5 \mathrm{~m}$ to nearest sub adult \\
\hline & & & $>20 \mathrm{~m}$ to nearest sub adult \\
\hline & & & $>1 / 2$ litter within five meters \\
\hline \multirow[t]{6}{*}{$\begin{array}{l}\text { Continuous } \\
\text { sampling }\end{array}$} & \multirow[t]{6}{*}{$\begin{array}{l}\text { Social } \\
\text { behaviours }\end{array}$} & \multirow[t]{4}{*}{$\begin{array}{l}\text { Agonistic } \\
\text { interactions }\end{array}$} & $\begin{array}{l}\text { Threatening: lowering the head opposite an adult or sub adult, clapping its jaws, uttering } \\
\text { short intensive snorts; rising the head and opening its jaws when turned to an adult or } \\
\text { sub adult; approaching an adult or sub adult with at least } 1 \mathrm{~m} / \mathrm{s} \text { when exposing the } \\
\text { throat; approaching an adult or sub adult when exposing the throat and snorting; } \\
\text { suddenly turning its head towards an adult or sub adult during feeding; turning towards } \\
\text { an adult or sub adult resulting in standing face to face }\end{array}$ \\
\hline & & & Biting: biting an adult or sub adult on its head or body \\
\hline & & & $\begin{array}{l}\text { Butting: butting in an adult's or sub adult's side; walking parallel to an adult or sub adult } \\
\text { butting its side }\end{array}$ \\
\hline & & & $\begin{array}{l}\text { Responding defensive: turning its head to the side and sometimes screaming as a response } \\
\text { to a threat from an adult or sub adult }\end{array}$ \\
\hline & & \multirow[t]{2}{*}{$\begin{array}{l}\text { Nose } \\
\text { contacts }\end{array}$} & $\begin{array}{l}\text { Nosing on or being nosed on the snout or head by adult or sub adult; nosing on the body of } \\
\text { adult or sub adult }\end{array}$ \\
\hline & & & $\begin{array}{l}\text { Nose contact with piglets: nosing on own piglet or being nosed on the snout or head by } \\
\text { own piglet. Each disctrete interaction between sow and piglet was counted, even } \\
\text { though if in sequence of nosings on several piglets or during simultaneously nosings } \\
\text { by several piglets }\end{array}$ \\
\hline
\end{tabular}




\section{Data analysis}

Data analysis was done for each sow for 14 days before and after the first day the sow was observed in nest with piglets (day 0), hereafter referred to as the farrowing period. All complete and un-interrupted 15 min observation sessions during a day were added up for a specific sow, and constituted the sample from that sow at that day. All data were analysed with the sow as statistical unit. $\mathrm{N}$ varied between one and 10 for different variables and days in the farrowing period. This variation was due to the sampling methods where some variables were not collected in 2003 and sows were not studied every day in the farrowing period. Also, there was a high piglet mortality where some sows lost their whole litters and therefore were excluded from further studies. When analysing data, a day in the farrowing period was excluded from statistics if $\mathrm{N}<3$.

Habitat use was analysed with the non-parametric Wilcoxon's test for matched pairs (Statistica 7.0) for comparisons of sows' means before and after farrowing. Sows were excluded from statistics if they, due to the already mentioned piglet mortality, had $<3$ days of recordings after farrowing. All deviations from the mean were calculated as standard error of the means (S.E.).

Based on the observed change in the variable " $0-5 \mathrm{~m}$ to nearest adult" and day 0 , the farrowing period was divided into 3 phases: Phase 1 = before farrowing, day -14 to -1 ("pre-farrowing"); Phase $2=$ after farrowing and isolation phase, day 1 to 8 ("isolation phase"); Phase 3= day 9-14 ("sociality phase"). Day 0 was referred to as the farrowing day, and not included in any of the three other phases. Differences between phases were analysed with non-parametric Wilcoxon's test for matched pairs (Statistica 7.0). Sows were excluded from a phase in the test if they had $<3$ days of recording in that phase. 
To examine whether the sows used the habitats randomly in relation to their availability, we calculated the habitat use in proportion to availability by dividing the frequency of habitat use by habitat availability. The number of agonistic interactions or nose contacts with adults and sub adults were calculated as a total per hour during the time spent 0-5 $\mathrm{m}$ to nearest adult or sub adult. 


\section{Results}

The most common activities during the farrowing period were resting $(38.4 \pm 1.8 \%, \mathrm{~N}=10)$, foraging $(36.1 \pm 2.3 \%, \mathrm{~N}=10)$ and locomotion $(13.9 \pm 3.3 \%, \mathrm{~N}=10))$. As seen in Fig. 1a, the overall pattern of behaviour changes was that resting increased day 0 , was highest in day 1 and thereafter tended to decrease. Furthermore, foraging and locomotion decreased to close to zero on day 0 and slowly increased again after farrowing (Fig. 1b and c). Statistical tests were carried out for differences between phases, and for resting, foraging and locomotion there was a significant difference between Phases 1 and $2(\mathrm{Z}=2.366, \mathrm{P}=0.018, \mathrm{~N}=7)$ and Phases 2 and $3(\mathrm{Z}=2.02, \mathrm{P}=0.043$, $\mathrm{N}=5)$. The average proportion of time spent nursing after farrowing was $11.1 \%( \pm 1.5, \mathrm{~N}=10)$ and there was a significant difference between Phases 2 and $3(\mathrm{Z}=2.022, \mathrm{P}=0.043, \mathrm{~N}=5)$ where the proportion of time spent nursing slowly decreased.

Before farrowing, the sows spent about half their time within $5 \mathrm{~m}$ of nearest adult (Fig. 2a). On the farrowing day (day 0 ) there was a tendency for an increase in proportion of time spent $>20 \mathrm{~m}$ to nearest adult (Fig. 2b). On the $9^{\text {th }}$ day the sows again spent more than half of their time within $5 \mathrm{~m}$ to nearest adult (Fig. 2a). The proportion of time sows spent either $0-5 \mathrm{~m}$ or $>20 \mathrm{~m}$ to nearest adult were almost identical to the proportion of time spent $0-5 \mathrm{~m}$ or $>20 \mathrm{~m}$ to nearest sub adult (no figures), except from the $9^{\text {th }}$ day where the sub adults still were $>20 \mathrm{~m}$ away most of the time. Again, statistical analysis was performed on the differences between phases, and there was a significant difference in proportion of time spent $0-5 \mathrm{~m}$ and $>20 \mathrm{~m}$ to nearest adult between Phases 1 and 2 $(\mathrm{Z}=2.366 \mathrm{P}=0.018, \mathrm{~N}=7)$ and between Phases 2 and $3(\mathrm{Z}=2.023, \mathrm{P}=0.043, \mathrm{~N}=5)$. During $95.6 \%( \pm$ 1.0, $\mathrm{N}=7$ ) of the observations, the sows had more than half of the litter within $5 \mathrm{~m}$ in Phases 2 and 3.

The frequency of agonistic interactions (a chategory of social behaviours including threatening, biting, butting and responding defensive; see Table 1) with adults and sub adults did not change 
a)

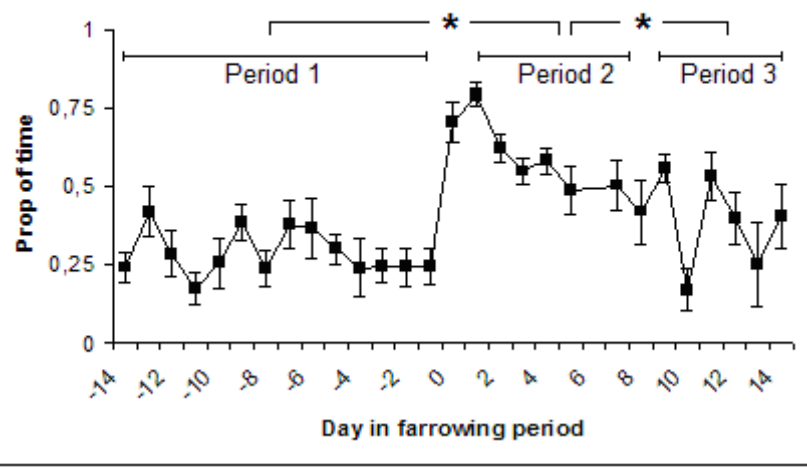

b)

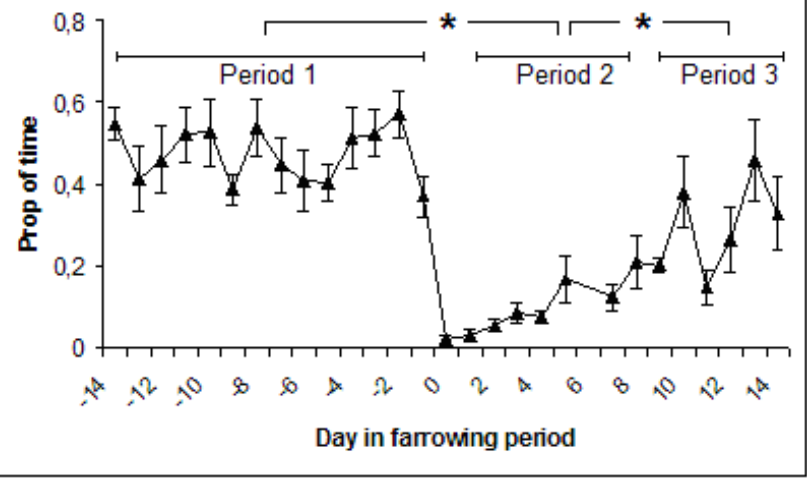

c)

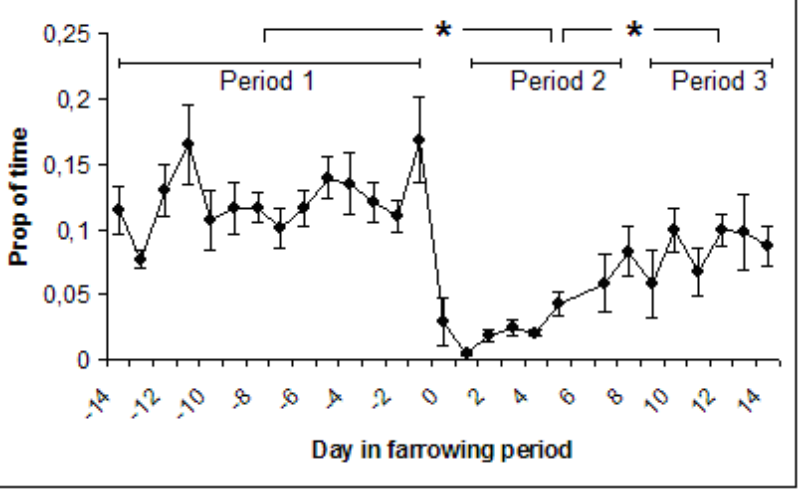

Fig. 1a-c. Changes in a) resting, b) foraging and c) locomotion during farrowing period. Abcissae = day in farrowing period, in relation to sows' first day in nest with piglet, called day 0 . Ordinates $=$ proportion of time spent on the activity. $\mathrm{N}=6-10$ in days -14 to $0, \mathrm{~N}=3-9$ in days 1 to 14 . 

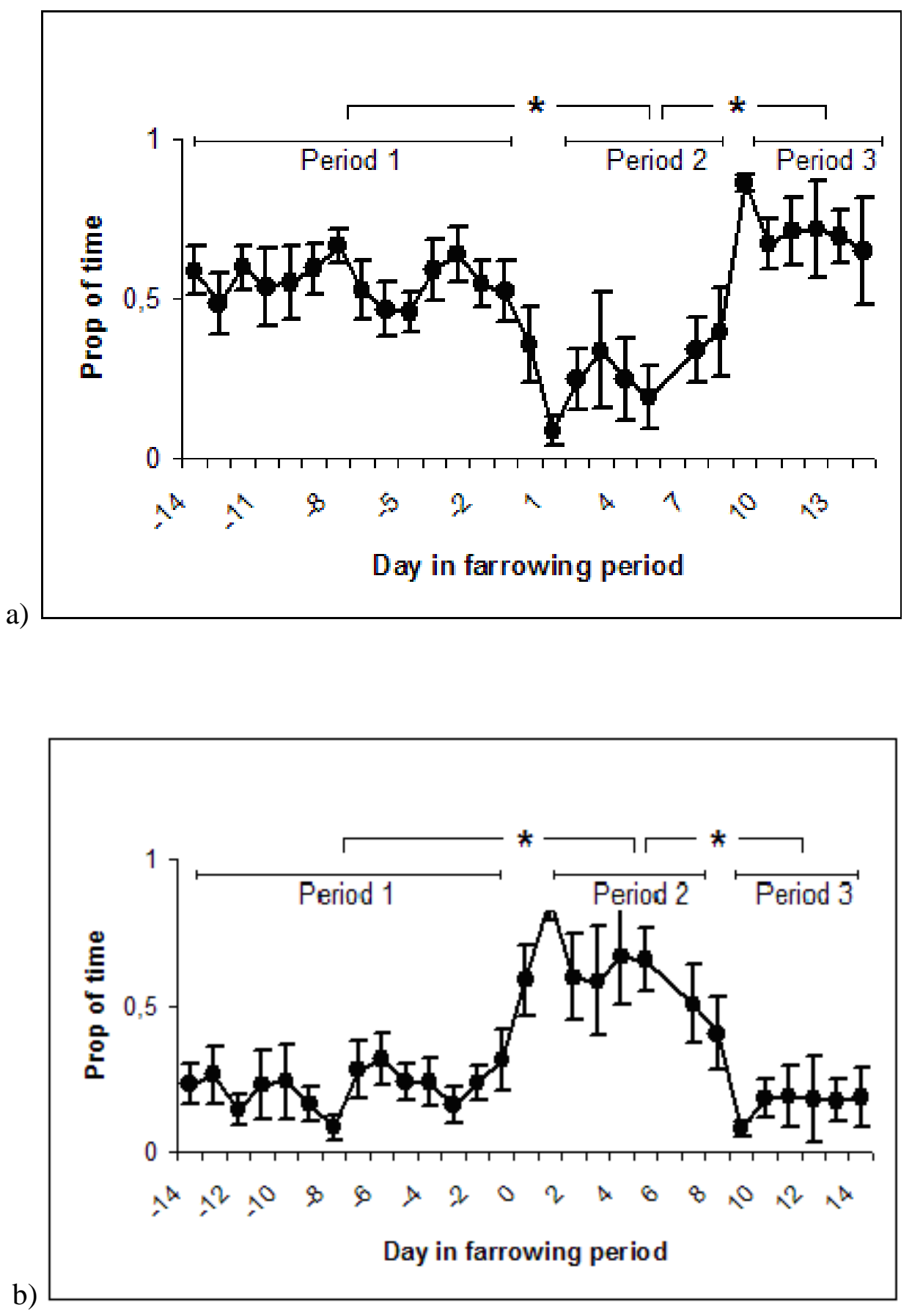

Fig. 2a and b. Sows' proportion of time spent at a) 0-5 m and b) $>20 \mathrm{~m}$ to nearest adult during farrowing period. Abcissae = day in farrowing period in relation to sows' first day in nest with piglets, called day 0 . Ordinates $=$ proportion of time. $\mathrm{N}=6-10$ in days -14 to $0, \mathrm{~N}=3-9$ in days 1 to 14 . 
much from day to day before farrowing (Fig. 3a). There were no significant changes in agonistic interactions between Phases 1 and $2(\mathrm{Z}=0.135, \mathrm{P}>0.05, \mathrm{~N}=5)$ or between Phases 2 and $3(\mathrm{Z}=1.604$, $\mathrm{P}>0.05, \mathrm{~N}=3$ ). The nose contacts increased after farrowing and then slowly decreased again (Fig. 3b) and there was a significant difference between Phases 1 and $2(\mathrm{Z}=2.023, \mathrm{P}=0.043, \mathrm{~N}=5)$. The frequency of nose contacts per piglet and hour increased the first three days after farrowing and decreased again on day 7 (Fig. 4), but there was no significant difference between Phases 2 and 3 $(\mathrm{Z}=1.753, \mathrm{P}=0.080, \mathrm{~N}=5)$.

The most visited habitats during the farrowing period were: edge $(32.0 \pm 4.5 \%)$, mixed forest $(22.5 \pm 7.2 \%)$, feeding area $(14.5 \pm 1.6 \%)$, field $(9.9 \pm 1.2 \%)$ and dense spruce forest $(8.3 \pm 3.1 \%)$ $(\mathrm{N}=6)$. Overall, the proportion of time spent in dense spruce forest and mixed forest increased after farrowing while the proportion of time spent in edge, field and feeding area decreased, but only for the two latter was the difference significant $(\mathrm{Z}=2.023, \mathrm{P}=0.043, \mathrm{~N}=5)$ (Fig. 5a).

Before farrowing, all habitats apart from feeding area were used in a proportion close to their relative availability (=1) (Fig. 5b), while the feeding area was used about 40 times more than expected in relation to its available area. After farrowing, the relative use of dense spruce forest and mixed forest increased and the use of field and feeding area decreased significantly $(\mathrm{Z}=2.023$, $\mathrm{P}=0.043, \mathrm{~N}=5)$.

The most commonly used habitats for farrowing nests $(\mathrm{N}=22)$ were edges (15 nests, $68 \%)$ and mixed forests (4 nests, $18 \%$ ), and the median distance to a feeding area was $130 \mathrm{~m}$ (min $65 \mathrm{~m}$, max $310 \mathrm{~m})$. A majority of the sows (16 sows, $73 \%$ ) had their nests in a slope facing south or had some kind of protection (e.g. vegetation or a rock) in the proximity of the nest and in a northerly direction.

Nest building was mostly performed during night time or otherwise outside the sampling sessions, so the behaviour could not be recorded in any detail. Casual observations were noted 

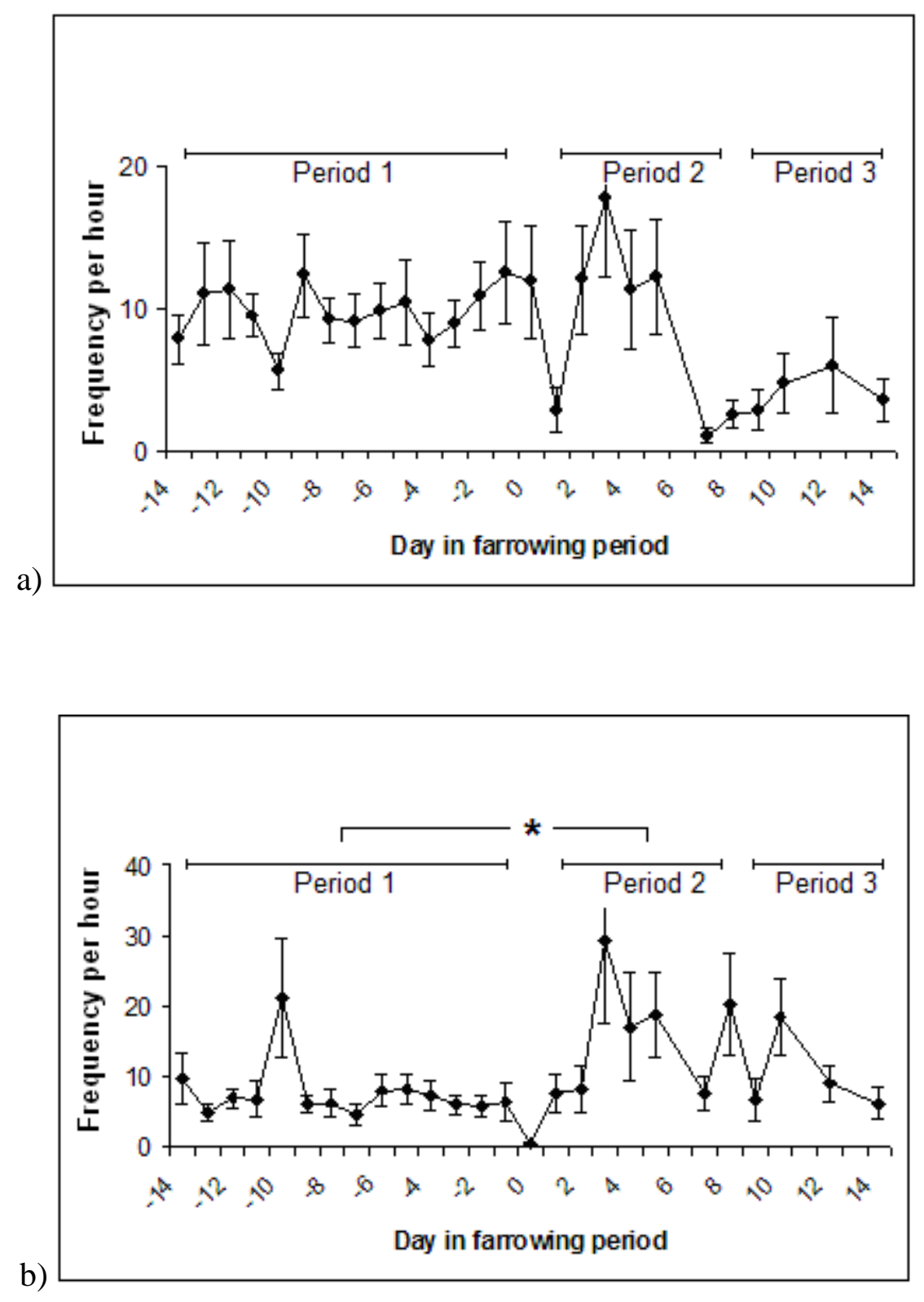

Fig. 3a and b. Agonistic interactions (a) and nose contacts (b) with adults and sub adults during time spent $0-5 \mathrm{~m}$ to nearest individual during farrowing period. Abcissae= day in farrowing period, in relation to sows' first day in nest with piglets, called day 0 . Ordinates $=$ frequency per hour of social interactions corrected with time spent $0-5 \mathrm{~m}$ to adults or sub adults respectively. $\mathrm{N}=4-6$ in days -14 to $0, N=3-5$ in days 1 to 14 . 


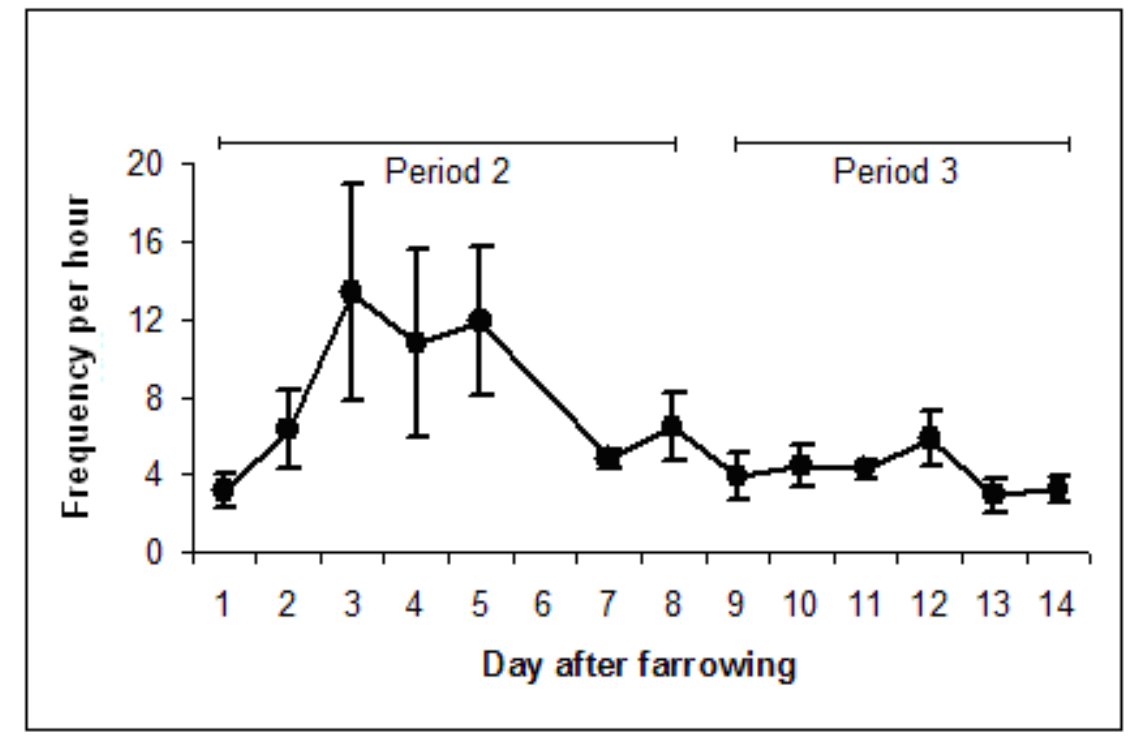

Fig. 4. Number of nose contacts from sows towards own piglets, numbers/h. Abcissa= day in farrowing period in relation to sows' first day in nest with piglets, called day 0 , Ordinate $=$ frequency of nose contacts per hour. $\mathrm{N}=3-9$.

without quantification, and involved digging with the snout in the beginning of the nest building, carrying of nest material from up to about $30 \mathrm{~m}$ from the nest, and arranging nest material with the feet and the snout. 

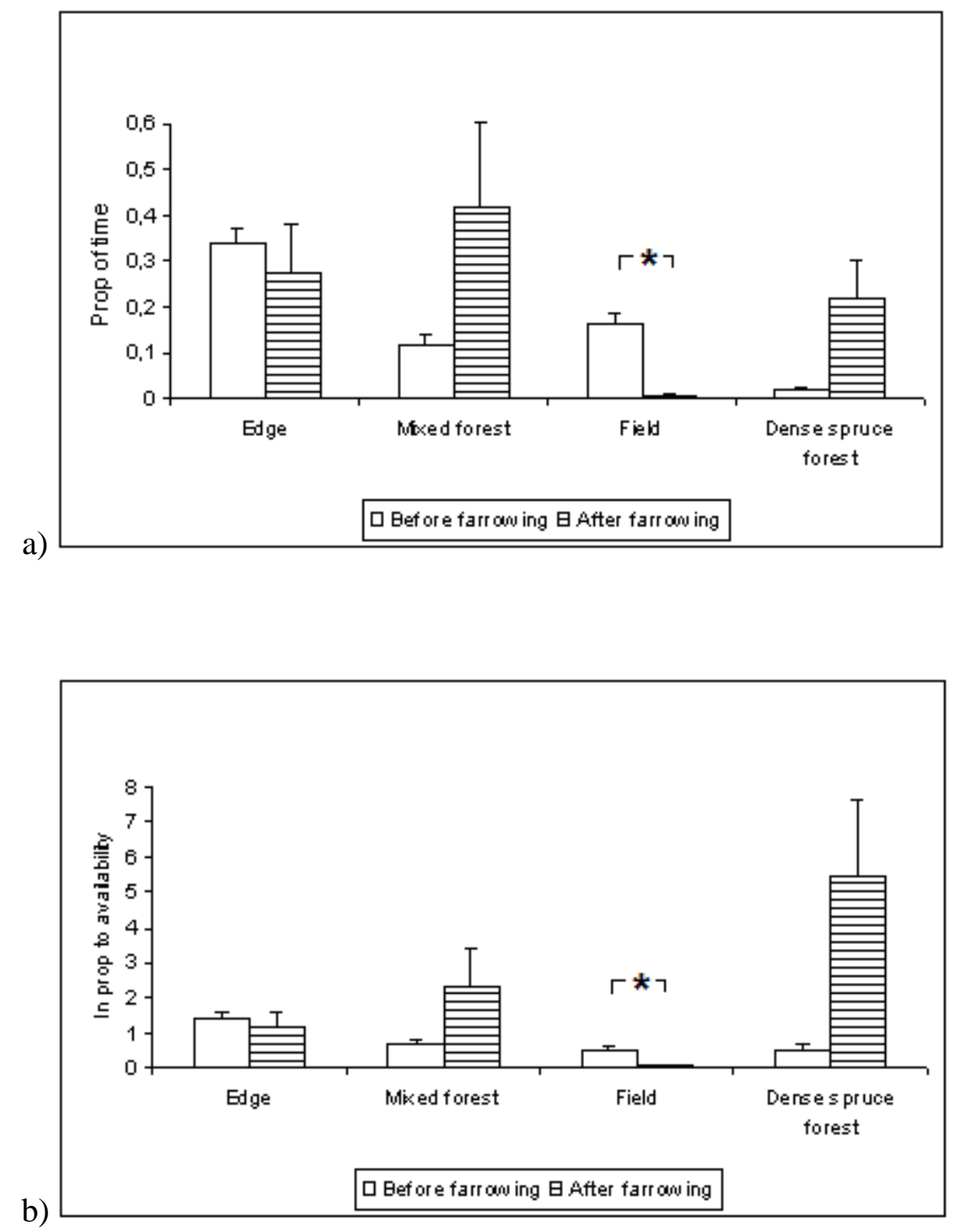

Fig. 5a and b. Habitat use during farrowing period in: a) proportion of time, ordinate= habitat use in proportion of time; b) in proportion in relation to habitat availability, ordinate $=$ habitat use in proportion to habitat availability. Proportion to availability $=1$ means that the habitat is used in same proportion as it is available. $\mathrm{N}=5$. 


\section{Discussion}

Even though scattered and non-quantified observations of various aspects of wild boar behaviour are abundant in the literature, this study is the first to provide integrative quantitative and systematic data demonstrating significant changes in wild boar behaviour in connection with farrowing. Our results showed that the farrowing process could be divided into three phases: the pre-farrowing, isolation and sociality phases (day -14 to -1 , day $1-8$ and day 9 to 14 respectively). Each phase was characterised by specific profiles in general activity and social behaviour. After farrowing the activity decreased, the distances to other adults increased, and habitat use changed towards more protective habitats. The maternal activities (social contact with piglets and nursing) gradually decreased after farrowing, indicating a gradual loosening of mother-offspring bonds, possibly paired with an increased necessity to feed for the sow, and a reduced need of milk on the part of the piglets. Hence, the farrowing period of the wild boar sow appears to be dynamic with changes in activity, sociality and habitat use. This needs to be taken into consideration when designing enclosures for the species.

During late pregnancy, when our studies started, the sows formed groups together with sub adults, which they left to become socially isolated at the time of farrowing. Gundlach (1968) reports on sows isolating from the group one to three days before farrowing, and, in our study, the interindividual distance increased on the farrowing day, indicating social isolation. The changes in individual distances allowed us to distinguish three distinct phases (pre-farrowing, isolation and sociality phase) in the farrowing period. The first phase shift was when the sows isolated from the family group and the second when the sows left their farrowing nests to form nursing groups with sows from their original family group. 
Social isolation before farrowing has been described previously in wild boars (Gundlach, 1968; Martys, 1982). Hirotani and Nakatani (1987) report that free-living Japanese wild boar dams (Sus scrofa leucomystax) drive their offspring away one month before farrowing, something not observed in this study. In accordance with earlier findings (Teillaud, 1986) the agonistic interactions decreased one week after farrowing, which was followed by the sociality phase.

The sows' nose contacts with piglets were most intense in the isolation phase. Interestingly, the frequency of nose contact with piglets did not change when the sows started to socialise in nursing groups and piglets from different litters were mixed. This suggests that bonding occurred during the isolation phase, as mentioned by Fernández-Llario (2004), which seems to correspond to the situation in domestic pigs (Horrell and Hodgson, 1992).

Our results on variation in foraging and locomotion showed some resemblance with earlier findings (Mauget, 1980a; Blasetti et al., 1988). However, we did not find any increase of general activity one day before farrowing as have been reported in Japanese wild boars (Eguchi et al., 1998) and in domestic pigs under semi-natural conditions (Jensen et al., 1987; Jensen et al., 1993). Locomotion and foraging decreased after farrowing, as has been indicated previously (Cousse and Janeau, 1992). The differences between our results and previous studies in the pre-farrowing activity may indicate that this aspect of the wild boar behaviour is flexible and dependent on differences between life conditions and data collection methods.

Farrowing changed the use of available habitats, similar to what has been observed by Spitz and Janeau (1995), so the sow and the piglets occupied more protective areas. Both in enclosures (Blasetti et al., 1988) and in the wild (Massei and Genov, 1995) wild boar choice of habitat is dynamic and different habitats are used differently depending on season. Our results are largely in agreement with those found by Boitani et al (1994) and Fernández-Llario et al. (1996). 
A majority of the studied sows built their nests in an edge between habitats, in agreement with what has been found by Dardaillon (1986), and facing south (agreeing with Janeau and Spitz, 1984). Edges might offer protection, but also enable screening of the surroundings. Facing south may enhance temperature maintenance in the nest.

The behaviour of the wild boars was strikingly similar to maternal behaviour earlier observed in domestic pigs kept under naturalistic conditions. Jensen et al. (1987) described how domestic sows left the group before farrowing, seeked out a suitable farrowing site remote from the normal home range, built a nest and stayed with the litter in the nest and its surroundings for about one week. This indicates that the basic structure of the maternal behaviour of wild boars has been relatively unaffected by domestication. This may have important implications for the welfare of intensely housed domestic sows.

Although we have studied the behaviour of a wild boar group over three successive breeding seasons, there are of course some limitations as to how wide the results can be generalised. We studied only one specific enclosure, and had a limited animal material. High piglet mortality decreased the statistical power of our comparisons. In spite of this, literature comparisons indicate that our data are representative, and could be used to make more precise predictions for further and more extended studies. They also offer important aspects to consider when designing enclosures for this species. For example, the isolation phase appears to be an important aspect of the maternal behaviour, and enclosures should therefore be designed so as to facilitate this behaviour.

\section{Acknowledgements}

The authors want to thank the owner of the enclosure, Göte Olsson, and animal keeper, Ingvar Larsson, for giving us full access to the enclosure and its animals. We also want to thank Nadine 
Smits, Edwin Jousmaa and Johan Rombin for help with collecting data. This study was financially supported by the Swedish Board of Agricultural Science, and the Swedish Animal Welfare Agency. 


\section{References}

Abaigar, T., del Barrio, G., Vericad, J.R., 1994. Habitat preference of wild boar (Sus scrofa L., 1758) in a mediterranean environment. Indirect evaluation by signs. Mammalia 58, 201-210.

Beuerle, W., 1975. Freilanduntersuchungen zum Kampf- und Sexualverhalten des europäischen Wildschweines (Sus scrofa L.). Z. Tierpsychol. 39, 211-258.

Blasetti, A., Boitani, L., Riviello, M.C., Visalberghi, E., 1988. Activity budgets and use of enclosed space by wild boars (Sus scrofa) in captivity. Zoo Biol. 7, 69-79.

Boitani, L., Mattei, L., Nonis, D., Corsi, F., 1994. Spatial and activity patterns of wild boars in Tuscany, Italy. J. Mammal. 75, 600-612.

Briedermann, L., 1971a. Ermittlungen zur Aktivitätperiodik des Mitteleuropaischen Wildschweines (sus s. scrofa L.). Zool. Garten N. F. Leipzig 40, 302-327.

Briedermann, L., 1971b. Zur Reproduktion des Swartzwildes in der Deutschen Demokratischen Republik. Tag. -Ber. dt. Akad. Landwirtsch. -Wiss. Berlin 113, 169-186.

Carranza, J., 1996. Sexual selection for male body mass and the evolution of litter size in mammals. Am. Nat. 148, 81-100.

Cousse, S., Janeau, G., 1992. Time budget and polyphasic activity in wild boar, Sus scrofa L. In: F. Spitz,G. Janeau,G. Gonzalez, S. Aulagnier (Eds.), Ongulés/Ungulates 91, pp. 391-394. ParisToulouse, France: S.F.E.P.M. - I.R.G.M.

Dardaillon, M., 1986. Seasonal variations in habitat selection and spatial distribution of wild boar (Sus scrofa) in the Camargue, southern France. Behav. Processes 13, 251-268.

Dardaillon, M., 1988. Wild boar social groupings and their seasonal changes in the Camargue, southern France. Z. Säugetierkunde 53, 22-30. 
Dardaillon, M., Teillaud, P., 1987. Éthogramme du sanglier adulte et du marcassin (Sus scrofa L). Monitore zool. ital. (N. S.) 21, 41-68.

Delcroix, I., Signoret, J.P., Mauget, R., 1985. L'élevage en commun des jeunes au sein du groupe social chez le sanglier. Journées recherche porcine en France 17, 167-174.

Delcroix, I., Mauget, R., Signoret, J.P., 1990. Existence of synchronization of reproduction at the level of the social group of the European wild boar (Sus scrofa). J. Reprod. Fert. 89, 613-617.

Eguchi, Y., Tanaka, T., Yoshimoto, T., 1998. Pre- and post-farrowing behaviour of Japanese wild boars, Sus scrofa leucomystax, in farrowing pens. In ISAE '98: Proceedings of the 32nd Congress of the International Society for Applied Ethology, (Ed. I.B. Veissier, A.), pp. 128 (Abstract). Clermont-Ferrand, France.

Fernández-Llario, P., 2004. Environmental correlates of nest site selection by wild boar Sus scrofa. Acta Theriol. 49, 383-392.

Fernández-Llario, P., Carranza, J., Hidalgo de Trucios, S.J., 1996. Social organization of the wild boar (Sus scrofa) in Doñana National Park. Miscellània Zoològica 19, 9-18.

Gundlach, V., H., 1968. Brutfürsorge, Brutpflege, Verhaltensontogenese und Tagesperiodik beim Europäischen Wildschwein (Sus scrofa L.), Zeitschrift für Tierpsychologie, vol. 25, pp. 955995. Hamburg: Paul Parey.

Henry, V.G., 1968. Length of estrous cycle and gestation in european wild hogs. J. Wildlife Manage. $32,406-408$.

Hirotani, A., Nakatani, J., 1987. Grouping-patterns and inter-group relationships of Japanese wild boars (Sus scrofa leucomystax) in the Rokko Mountain area. Ecol. Res. 2, 77-84.

Horrell, I., Hodgson, J., 1992. The bases of sow-piglet identification. 1. The identification by sows of their own piglets and the presence of intruders. Appl. Anim. Beh. Sci. 33, 319-327. 
Janeau, G., Spitz, F., 1984. L'espace chez le sanglier (Sus scrofa scrofa L.) occupation et mode d’utilisation. Gibier Faune Sauvage 1, 73-89.

Jensen, P., Redbo, I., 1987. Behaviour during nest leaving in free-ranging domestic pigs. Appl. Anim. Beh. Sci. 18, 355-362.

Jensen, P., Florén, K., Hobroh, B., 1987. Peri-parturient changes in behaviour in free-ranging domestic pigs. Appl. Anim. Beh. Sci. 17, 69-76.

Jensen, P., Stangel, G., Algers, B., 1991. Nursing and suckling behaviour of semi-naturally kept pigs during the first 10 days postpartum. Appl. Anim. Beh. Sci. 31, 195-209.

Jensen, P., Vestergaard, K., Algers, B., 1993. Nestbuilding in free-ranging domestic sows. Appl. Anim. Beh. Sci. 38, 245-255.

Kaminski, G., Brandt, S., Baubet, E., Baudoin, C., 2005. Life-history patterns in female wild boars (Sus scrofa): mother-daughter postweaning associations. Can. J. Zool. 83, 474-480.

Martin, P., Bateson, P., 1993. Measuring Behaviour. Cambridge, Cambridge University Press. Martys, M., 1982. Gehegebeobachtungen zur Geburts- und Reproduktionsbiologie des Europäischen Wildschweines (Sus scrofa L.). Zeitschrift für Säugetierkunde 47, 100-113.

Massei, G., Genov, P., 1995. Preliminary analysis of food availability and habitat use by the wild boar in a mediterranean area. Ibex J. Mount. Ecol. 3, 168-170.

Mauget, R., 1980a. Régulations écologiques, comporta-mentales et fisiologiques (function de reproduction) de l'adaptation du sanglier au milieu, pp. 299+XXXIII. France: Univer. de Tours-Orleans.

Mauget, R., 1980b. Home range concept and activity patterns of the European wild boar (Sus scrofa L.) as determined by radio tracking. In: C.J. Amlaner, D.W. MacDonald (Eds.), A handbook on biotelemetry and radio tracking. New York: Pergamon Press Inc. 
Spitz, F., Janeau, G., 1995. Daily selection of habitat in wild boar (Sus scrofa). J. Zool., Lond. 237, 423-434.

Stegeman, L.C., 1938. The European wild boar in the Cherokee national forest, Tennessee. J. Mammal. 19, 279-290.

Teillaud, P., 1986. Strategies alimentaires et statut social chez le sanglier en captivite. Behav. Processes 12, 327-347. 